\title{
Die Heidelbergse Kategismus in Afrikaans: 'n Eerste blik op die eerste halfeeu
}

\author{
JP Oberholzer
}

\begin{abstract}
The Heidelberg Catechism in Afrikaans: A first glance at the first half century.

The publication of the first Afrikaans translation of the Heidelberg Catechism in 1936 caused considerable controversy on account of the translated Dutch text. The translation as well as the Dutch original is examined and found to be of a high standard. Some observations are made on the handling of the Catechism by synods itself and the Scripture references accompanying the text.
\end{abstract}

Die halfeeu waarvan hier sprake is, behoort tot die tweede deel van die werksaamheid van die geëerde persoon aan wie hierdie bundel opgedra word. Na die beste van my wete het prof $\mathrm{CH}$ Rautenbach self geen aandeel gehad in die kontroverse wat hier aan die lig gebring word nie. Tog gaan dit oor 'n stuk geskiedenis wat hy self deurleef het, en word hierdie bydrae hom aangebied met hoë agting en met waardering vir wat hy ook vir my beteken het. Dit pas dat na verloop van vyftig jaar daar aandag gegee word aan 'n gebeurtenis en sy naspel wat blywende betekenis vir kerk en teologie in ons land gehad het.

Die eerste Afrikaanse vertaling van die Belydenisskrifte tesame met die liturgiese geskrifte het in 1936 verskyn onder die titel Die Drie Formuliere van Enigheid en die Liturgie. Die res van die titelblad lui:

In Afrikaans vertaal deur die Bybelvertalers, in opdrag van die Gesamentlike Kommissie verteenwoordigende die Drie Hollandse Kerke in Suid-Afrika. Uitgegee deur die Suid-Afrikaanse Bybelvereniging, Kerkstraat 9, Kaapstad. Nasionale Pers, Beperk, Kaapstad, 1936.

Soos mettertyd gebruiklik geword het, volg die Heidelbergse Kategismus ná die Nederlandse Geloofsbelydenis. Die Kategismus beslaan bladsye 34 tot 77 . 
Oor die opdrag waarna op die titelblad verwys word, was daar verskil van mening. Reeds in 1927 rapporteer ds CWM du Toit aan die sinode van die Gereformeerde Kerk 'dat die kommissie uit die drie Hollandse Kerke wat toesig hou oor die vertaling van die Bybel en ook te doen het met die vertaling van ons liturgiese formuliere en belydenisskrifte besluit het met die oog op vele moeilikhede in verband met die oorsetting, dat die werk sal gedoen word deur die vertalers van die Bybel'. Op dieselfde vergadering dien 'n skrywe van ds LE Brandt, voorsitter van die Kommissie van die Algemene Kerkvergadering van die Nederduitsch Hervormde Kerk, gedateer 16 November 1926, waarin hy meedeel dat die Kommissie 'in hare vergadering van 28 Oktober besloten heeft uwe uitnodiging aan te nemen om samen te werken aan de vertaling in het Afrikaans van de Confessie en Liturgiese formulieren en als haar verteenwoordiger in deze zaak benoemd heeft prof SP Engelbrecht van Pretoria' (Handelinge Gereformeerde Kerk 1927, Notule: 63,68$)$. Dit kom dus voor of daar 'n verandering van voorneme gekom het. Waar die bedoeling aanvanklik was dat 'n interkerklike kommissie die vertaling sou doen, is die vertaling laat in 1926 of vroeg in 1927 opgedra aan die Bybelvertalers. Op die Algemene Kerkvergadering van die Nederduitsch Hervormde Kerk was daar in 1931 egter blykbaar geen kennis van die opdrag aan die Bybelvertalers nie, want daar is opdrag gegee aan 'n kommissie om 'n Afrikaanse vertaling te maak, en daarby word vermeld: 'Prof Engelbrecht wys op die verskillende uitgawes van die Formuliere en Liturgiese Geskrifte. Die Susterkerk wil 'n uitgawe gebruik wat afwyk van die uitgawe wat ons Kerk in gebruik het.' (Notule Algemene Kerkvergadering 1931: 98). Drie jaar later rapporteer die Kommissie vir die Vertaling van die Formuliere en Liturgiese Geskrifte dat die vertaalwerk tussen sy lede verdeel is, maar dat daar mondelings verneem is dat die Bybelvertalers reeds met die werk besig is. Verder word gemeld dat die Kommissie van die Algemene Kerkvergadering in September 1933 besluit het om die vertaalwerk aan die Bybelvertalers oor te laat (Notule Algemene Kerkvergadering 1934: 24). Die besluit van die Kommissie van die Algemene Kerkvergadering waarna verwys word, word soos volg gerapporteer:

Die Skriba lees 'n brief van ds ES Mulder as Sekretaris van die Kommissie vir die vertaling van die Liturgiese Geskrifte. Die kommissie wil weet of hy moet aangaan met die vertaling volgens opdrag van die laaste Algemene Vergadering of dat dit moet oorgelaat word aan die Bybelvertalers, wat reeds besig is om hierdie geskrifte in Afrikaans oor te sit. Die Vergadering ag dit 
gewens dat daar eenheid sal wees in die drie Hollandse Kerke van Suid-Afrika wat betref die formuliere en liturgiese geskrifte en beveel daarom aan 1. dat die vertaalwerk aan die Bybelvertalers sal oorgelaat word, 2 . dat die teks wat vertaal moet word deur die Kommissie vir die vertaling van die Liturgiese Geskrifte sal aangegee word met motivering waarom juis daardie teks gekies is, 3. dat Formuliere en Liturgiese Geskrifte of gedeeltes daarvan wat alreeds vertaal is, opgestuur sal word aan die Bybelvertalers om daarvan gebruik te maak (Notule, Kommissie van die Algemene Kerkvergadering 6 September 1933: 205).

Ná die verskyning van die vertaling wat deur die Bybelvertalers gemaak is, rapporteer die Kommissie van die Algemene Kerkvergadering aan die Algemene Kerkvergadering van 1937 dat hy met groot blydskap kennis geneem het van die verskyning van die vertaling en beveel hy die ontbinding van die Nederduitsch Hervormde Kerk se eie vertalingskommissie aan. Die vergadering het egter anders oor die saak gedink. Die betrokke kommissie is nie ontbind nie, maar het opdrag gekry om die vertaling van die Bybelvertalers te bestudeer en aan die Kommissie van die Algemene Kerkvergadering te rapporteer (Notule, Algemene Kerkvergadering 1937: 21).

Die vertaling het in die Gereformeerde Kerk volkome byval gevind. 'n Benoemde kommissie rapporteer in 1939 aan die Gereformeerde Sinode te Bloemfontein:

1. Dat dit ' $n$ baie geslaagde oorsetting is van die deur onse Kerk goedgekeurde teks, soos vasgestel deur die Gereformeerde Kerke in Nederland en in die Nederlandse Taal uitgegee deur drs Rutgers, Bavinck en Kuyper.

2. Dat in die teks van die formuliere van Enigheid geen veranderings aangebring is nie (Handelinge Gereformeerde Sinode 1939: 39).

Inderdaad het die vertaling van die Bybelvertalers in die Gereformeerde Kerk diens bly doen totdat met die goedkeuring van die nuwe interkerklike vertaling van 1982 die uitfasering daarvan begin het.

In die Nederduits Gereformeerde Kerk het die Kaapse Sinode van 1936 sy dank teenoor die Bybelvertalers uitgespreek, maar terselfdertyd versoek dat die Raad van die Gefedereerde Kerke 'n kommissie sal benoem om die Afrikaanse Formulierboek na te sien en dat hulle 'die vrug van hulle arbeid (desnoods met aanbevelings) sal voorlê aan die 
geagte vertalers, om also gesamentlike optrede en samewerking te verseker, met die oog op die verkryging van 'n Formulierboek (by die eersvolgende herdruk) wat in beide vorm en inhoud so goed as moontlik sal wees' (Handelinge Sinode Nederduits Gereformeerde Kerk in Suid-Afrika 1936: 247). Reeds in 1940 vra die Suid-Afrkaanse Bybelvereniging 'dat teneinde één goedgekeurde oorsetting in Afrikaans van ons Liturgiese Geskrifte te verkry vir afdruk in ons Psalm- en Gesangboek die H E Vergadering die nodig stappe neem vir die daarstelling van 'n interkerklike kommissie bestaande uit verteenwoordigers van ons NG Kerk, die Geref. Kerk en die Ned. Hervormde Kerk' (Handelinge Sinode NG Kerk in SA 1940: 176). Hiervan het blykbaar niks tereggekom nie, want die Raad van die Gefedereerde Kerke het in Maart 1943 besluit om by die sinodes aan te beveel:

i. Dat ' $n$ kommissie bestaande uit dr BB Keet, prof GM Pellisier en ds JPH Steyn aangestel sal word om die vertaling grondig te hersien met inagneming van die besluite van hierdie Raad en van die verskillende Sinodes daaroor. ii. Dat verder 'n hersiene vertaling vir goedkeuring voorgelê sal word aan die Sinodale Kommissies of Sinodes van die NG Kerke, en dat sodanige goedkeuring die aanvaarding deur die Kerk van die Formuliere in Afrikaans sal beteken (Scriba Sinodi 23 Julie 1943).

Hierdie besluit van die Raad van Kerke lei dan uiteindelik tot die Formulierboek van die Gefedereerde Nederduitse Gereformeerde Kerke in Suid-Afrika, Kaapstad, Pretoria, 1950.

Ook die Nederduitsch Hervormde Kerk het uiteindelik sy eie weg gegaan. Op die Algemene Kerkvergadering van 1942 rapporteer die Kommissie vir die vertaling van die Liturgiese Geskrifte dat hy dit as sy vernaamste taak beskou het 'om die deur die Bybelvertalers in Afrikaans oorgesitte Belydenisskrifte, Formuliere en Gebede te vergelyk met die Nederlandse en waar nodig met die Franse, Duitse, Latynse en Griekse grondtekste'. Die kommissie wys dan op 'n aantal afwykings en kry opdrag om met die hersiening voort te gaan. Dit loop dan uit op die publikasie van die Belydenisskrifte, Gebede en Formuliere van die Nederduitsch Hervormde Kerk van Afrika, Pretoria, 1945. In die voorwoord van hierdie publikasie, wat nie in die handel beskikbaar is nie, word gemeld dat vir die simboliese geskrifte die uitgawe van JJ van Toorenenbergen gebruik is waarmee die uitgawe van MJ Goddefroy ooreenstem. Verder word gestel:

Daar is met opset gestreef om aansluiting te soek by 'n Afrikaanse 
oorsetting wat deur die kommissie van die Afrikaanse Bybelvertalers vervaardig is, wat egter gebaseer is op ' $n$ gewysigde teks wat die Sinode van die Gereformeerde Kerk van Nederland eers in 1934 aangeneem het, en wat verskillende afwykings van die bogenoemde in die Nederduitsch Hervormde Kerk gangbare teks vertoon, afwykings wat deur ons dan ook nie aanvaar is nie.

Die besware wat bestaan het, was dus nie teen die kwaliteit van die Bybelvertalers se werk gerig nie, maar teen die Nederlandse grondteks wat gebruik is. Hierdie teks was volgens ' $n$ memorandum van die Bybelvertalers 'die bekende "Flakkeesche" uitgawe van 1908 deur prof FL Rutgers besorg, wat getrou ' $n$ herdruk is van die oorspronklikoffisiële uitgawe' (Handelinge Sinode NG Kerk in SA 1936: 246). Hiermee word kennelik bedoel: 'De Berijmde Psalmen met eenige gezangen in gebruik bij de Gereformeerde Kerken in Nederland; alsmede hare Formulieren van Eenigheid, met de drie oude Geloofsbelijdenissen, en hare Liturgie, met het Kort Begrip en den Ziekentroost. Naar den door die kerken vastgestelden tekst uitgegeven door dr FL Rutgers onder medewerking van dr H Bavinck en dr A Kuyper, Flakkeesche Boekdrukkerij, Middelharnis, 1898', later herdruk. Tot my beskikking is dieselfde teks, maar wat verskyn het by Uitgewers-genootschap 'Biblia', Maassluis 1913.

Voordat aandag gegee word aan die kwaliteit van die Rutgersteks, moet 'n oomblik stilgestaan word by die kwaliteit van die Afrikaanse vertaling van 1936 (voortaan genoem $A$ 1936). 'n Vergelyking toon dat die vertalers se aanspraak dat hulle 'sonder enige wysiging' vertaal het, minstens ten opsigte van die Heidelbergse Kategismus bevestig word. Slegs in enkele gevalle kan 'n vraagteken geplaas word bo die Afrikaanse weergawe. Dit val op dat in Vraag en Antwoord 1 'beide in het leven en sterven' weergegee word met 'in lewe en in sterwe', 'n weergawe waaraan JD du Toit reeds in 1930 voorkeur gegee het (Die Heidelbergse Kategismus, Deel II 1930). Met die herhaling van 'in' en 'n geïmpliseerde klem op 'en' is dit in elk geval 'n goeie weergawe. Dit is egter te betwyfel of aan die einde van Antwoord 1 'verder' as 'n volledige weergawe van 'voortaan' kan geld. 'Om verder vir Hom te lewe' kan immers beteken om voort te gaan om vir Hom te lewe, terwyl 'om voortaan vir Hom te lewe' (Duits 'forthin', Latyn 'deinceps') die gedagte inhou van 'hiervandaan, van nou af'. Net so het 'n mens die gevoel dat in Antwoord 4 'in hoofsaak' nie weergee wat 'in eene hoofdsom' beliggaam is nie. Die Afrikaanse vertaling van 1982 (A 1982) 
is hier in die kol met 'samevattend'. A 1936 se weergawe van 'tot genade komen' in Vraag 12 met 'genade (kan) verkry' bring 'n verskuiwing in die rigting van 'n meer aktiewe menslike handeling wat nie teenwoordig is in die bronteks nie. Hier weer eens is $A 1982$ se 'in genade aangeneem word' 'n meer getroue weergawe. Vraag 14 lui in die Rutgersteks ( $R$ 1913) 'Kan ook ergens een bloot schepsel gevonden worden, dat voor ons betale?' Dit is in A 1936 weergegee met 'Kan daar ook êrens enige skepsel gevind word om vir ons te betaal?' Hier, net soos in die antwoord, het daar iets verloren gegaan, maar aan die ander kant is ' $n$ 'skepsel' nie minder of meer as 'n 'blote skepsel' of 'n 'loutere skepsel' nie. Eintlik is dit net die 'enige' en die 'geen enkele' wat 'n nuanse bybring wat nie in dié mate in $R 1913$ aanwesig is nie. In Antwoord 18 het $R, 1913$ afgewyk van sy bronteks (waaroor daar hieronder gehandel sal word) en het $A 1936$ op sy beurt afgewyk van $R$ 1913 deur te vertaal: 'Onse Here Jesus Christus wat deur God aan ons geskenk is tot wysheid, regverdigheid, heiligmaking en verlossing', terwyl $R 1913$ 'en tot eene volkomene verlossing' het. Hier het $A 1936$ dus korrektief opgetree teenoor $R$ 1913. Dit is moeilik om te verklaar waarom in Vraag 19 A 1936 gekies het vir 'word alle mense dan weer deur Christus verlos' in plaas van 'deur Christus salig' soos dit in $R 1913$ en trouens in alle ander uitgawes staan. Hier is in elk geval afgewyk in die rigting van wat na 'n suiwerder formulering lyk, 'n formulering wat Du Toit ook in Die Heidelbergse Kategismus, Deel II opgeneem het. Seker die mins-geslaagde weergawe, ook uit 'n verstaansoogpunt, is dié in Antwoord 26: 'en ook al die kwaad wat Hy oor my in hierdie jammerdal beskik, my ten beste bestuur' as weergawe van '... mij ten beste keeren' in $R 1913$ en ander uitgawes, waarvan de korrekte betekenis deur $A 1982$ uitgedruk word: 'tot my beswil verander'. Ons kan hierdie beskouing afsluit met ' $n$ laaste interessante afwyking. Dit is naamlik die geval van Antword 103 waar $R 1913$ in navolging van sy bronteks, in ooreenstemming met die Duitse en Latynse tekste en met die Nederlandse tekstradisie in sy geheel, soos volg lees: '. . . en dat ik, inzonderheid op den Sabbath, dat is, op den rustdag, tot de gemeente Gods naarstiglijk kome'. A 1936 vertaal hier: '. . met die gemeente van God ywerig moet opkom'. Ook hier kan vermoed word dat leerstellige oorwegings 'n rol gespeel het.

Ons kan tot die gevolgtrekking kom dat $A 1936$ oor die algemeen 'n getroue weergawe van $R 1913$ is; die enkele afwykings val daarom des te meer op. Voordat ons van die vertaling self afstap, moet daar tog nog 'n vraag gestel word, naamlik waarom die Bybelvertalers nie ten opsigte 
van die Kategismus meer aandag gegee het aan die Duitse en Latynse vorms van die Kategismus nie. Rutgers het dit wel gedoen en behoorlik daarvan rekenskap gegee. Die Bybelvertalers meld in hulle memorandum dat die Rutgersteks 'n getroue herdruk is van die oorspronklikoffisiële uitgawe (Handelinge Sinode NG Kerk in SA 1936: 246). Prof B Gemser, voorsitter van die Kommissie vir die Liturgiese Geskrifte van die Nederduitsch Hervormde Kerk skryf op 1 Desember 1943 egter aan die Kommissie van die Algemene Kerkvergadering dat sy Kommissie 'hoop om in die eerste week van die Nuwe Jaar gereed te kom met ons bewerking in Afrikaans na die oorspronklike teks soos reeds eeue lank hier in Suid-Afrika en ook by die Hervormde Kerk van Nederland in gebruik, waarvan die teks soos deur die Bybelvertalers gebruik en in Afrikaans oorgeset aanmerklik afwyk, veel meer as wat ons Kommissie oorspronklik gedink het'. Dié aanmerklike afwyking geld nie die Kategismus nie, want in 'n rapport aan die Algemene Kerkvergadering in 1942 noem die Kommissie vir die Kategismus slegs drie gevalle waar die teks sou afwyk van 'die oorspronklike teks'. Wat die Kategismus betref, is die Belydenisskrifte, Gebede en Formuliere van die Nederduitsch Hervormde Kerk van Afrika, 1945 (verder $A 1945$ genoem) dan ook in werklikheid 'n verwerking van $A$ 1936. Dié verwerking het plaasgevind aan die hand van JJ van Toorenenbergen De symbolische schriften der Nederlandsche Heroormde Kerk in gebruik, zuiveren kritisch bewerkten teks haar aangeboden tot wettig gebruik waarvan die tweede hersiene uitgawe in 1906 verskyn het. Van Toorenenbergen sluit baie nou aan by die Datheenteks van 1566, en die teks uit die eerste uitgawe van sy werk is deur MJ Goddefroy oorgeneem toe hy in 1897 De Belijdenisschriften van de Nederduitsch Hervormde Kerk gepubliseer het. Met 'die oorspronklike teks soos reeds eeue lank hier in Suid-Afrika en ook by die Hervormde Kerk van Nederland in gebruik', bedoel Gemser dus die Datheenteks, wat aanvaar is as die textus receptus in die Nederlandssprekende wêreld en homself as sodanig bly handhaaf het tot in hierdie eeu. Die gestalte van die Datheenteks waaroor dit vir Gemser gegaan het, was egter nie dié wat deur die uitgewers van die Bybel en die Psalm- en Gesangboek oorgelewer en gereeld in spelling aangepas is nie, maar dié wat deur Van Toorenenbergen langs kritiese weg weergegee is deur vergelyking van die Datheenteks met die Duitse en Latynse vorme.

Die Rutgersteks is op sy beurt ook 'n gestalte van die Datheenteks, maar via ' $n$ besondere Nederlandse teks waaraan ' $n$ besondere status toegeken is. Hierdie besondere teks was die bewerking wat in opdrag van die Provinsiale Sinode van Zeeland uitgegee is deur Herman 
Faukelius en wat in 1611 in Middelburg verskyn het onder die titel Catechismus ofte Onderwijsinghe in de Christelicke Leere, alsoo die in de kercken ende scholen der keurvorstelicken Paltz, ende der Nederlanden gheleert wort ( $M$ 1611). Rutgers, verantwoord hom daaroor soos volg in 'n kort voorwoord by sy weergawe van die kategismus:

Daar de Nederlandsche Kerken voor haren Catechismus geen authentieken tekst hebben vastgesteld, hetzij in hare Generale Synoden of wel door bezorging van eene officieele uitgave, en daar onder de Nederduitsche uitgaven, die althans eenig officieel karakter hebben, de bedoelde uitgave van het jaar 1611, die op last en gezag van de Privinciale Zeeuwsche Synode het licht zag, niet alleen de oudste is, maar ook algemeen erkend wordt als de beste en de meest gezaghebbende, is voor den ganschen Cateschismus de tekst van die uitgave hier ten grondslag gelegd; en bij iedere eenigszins belangrijke afwijking, die om taalkundige redenen, of ter wille van den oorspronkelijken (Duitschen en Latijnschen) tekst, of met het oog op andere betrouwbare Nederduitsche uitgaven, noodzakelijk scheen, is daarvan in eene noot rekenschap gegeven.

Bakhuizen van den Brink het 'n goeie saak daarvoor uitgemaak dat $M$ 1611 inderdaad die teks was wat in die Dordtse sinode gedien het en dus die naaste kom aan 'n geapprobeerde teks (Bakhuizen van den Brink 1976: 37, 40). Die publikasiegeskiedenis van die Kategismus in Nederlands bevestig egter nie dat dié opvatting gedeel is deur die Nederlandse kerk van die sewentiende en agtiende eeu nie. Veeleer kom dit voor of Rutgers en sy medewerkers met hierdie publikasie doelbewus ' $n$ stap gegee het in die rigting van ' $n$ amptelik goedgekeurde teks vir die Gereformeerde Kerk in Nederland, soos die titelblad inderdaad aandui. Ek was nie in die geleentheid om in te gaan op Bakhuizen van den Brink se opmerking dat die Rutgersteks 'niet berust op eenige vaststelling door een Gereformeerde Synode, maar alleen op het wetenschappelijk oordeel der uitgevers' (Bakhuizen van den Brink 1940: 44). Hoe dit ook al sy, die Rutgersteks skep die indruk van 'n deeglik oorwoë en wetenskaplik verantwoorde werk. Sy teruggryping na $M 1611$ het krities geskied, met inagneming van die talle kleiner wysigings wat die Kategismusteks vanaf 1611 ondergaan het èn met 'n deeglike verantwoording teenoor die teks in sy vroegste gestaltes. Lank nie al die verskille tussen $M 1611$ en $R 1913$ berus op Rutgers, Kuyper en Bavinck se eie besluite nie. 
Die verskille bestaan eerstens uit vervanging van woorde en uitdrukkings op grond van semantiese oorwegings. Hiervan gaan 'n aantal terug op wysigings wat met verloop van tyd aangebring is in opeenvolgende kategismusuitgawes. In die lys wat volg, verskyn in die eerste kolom die woorde soos dit voorkom in $M 1611$ en in die tweede die woorde waarmee dit in $R 1913$ vervang is, met tussen hakies die jaartal waarin die verandering ongeveer in kategismusuitgawes plek gekry het.

\begin{tabular}{|c|c|}
\hline & M 1611 \\
\hline 1. ens & lijf \\
\hline 1. & daerom \\
\hline 3. & ellendicheyt \\
\hline 4.22 & summa \\
\hline 14. ens & creature \\
\hline 17.18 & een waerachtigh God \\
\hline 19. & naemaels \\
\hline 27. & tegenwoordige \\
\hline 31. & sijn woordt ende sijnen Geest \\
\hline $\begin{array}{l}34 . \\
47 .\end{array}$ & $\begin{array}{l}\text { met goudt ofte silver } \\
\text { alsoo }\end{array}$ \\
\hline 53. & een waerachtigh eeuwich God \\
\hline 55. & kennen \\
\hline 60. & iae als hadde ick \\
\hline 69. & vleesches \\
\hline 70. & met den bloede ende Gheest \\
\hline 20. & ginse \\
\hline
\end{tabular}

\section{R 1913}

liggaam (1867)

waarom (1867)

ellende (1867)

hoofdsom (1867)

schepsel (1867)

waarachtig God (1867)

daarna (1867)

alomtegenwoordige (1650)

zijn Woord en Geest (1650)

met goud of met zilver (1615)

gelijk (1867)

waarachtig en eeuwig God (1650)

weten (1615)

ja, als hadde ik zelf (1615)

lichaams (1869)

met het bloed en den Geest

(1867)

begin (1867)

Daarnaas is daar wysigings wat deur Rutgers self aangebring is uit semantiese oorwegings. Van die meeste het hy verantwoording gedoen in voetnotas. Enkele van dié wysigings word genoem:

\section{1611}

1.123 gewelt

20.21.53.60 oprecht

21.

31.

32.

36.

44.

48.

55.

62. seker (weten)

seker (vertrouwen)

voortredet

bekennen

overcomt

quale

onbegrijpelick

aan te legghen

ghelijkmatig
R 1913

heerschappij

waar

stellig

vast

tusschentreedt

belijden

verkrijgt

kwelling

door niets kan ingesloten

worden

aan te wenden

gelijkvormig 


\section{1611}

85. niet afstaan willen

niet en vraghen

95. versieren

98. lijden

103. viere

105. ghelaet

108. tuchtelick

$110 . \quad$ onrechten

112. verkeere

121. toegedaen

125. bekennen

127. behouden
R 1913

niet willen aflaten

niet storen

verzinnen

dulden

ruste

gebaar

ingetogen

vals

verdraaie

bijgevoegd

erkennen

staande houden

Tweedens was daar wysigings waarmee Rutgers die teks van $M 1611$ gekorrigeer het, meesal in aansluiting by korreksies wat al vroeër aanvaar is en by ouer uitgawes aan die Datheenteks of by die Duitse of Latynse teks aansluit.

\section{$M 1611$}

18. ende verlossinghe

23. ten derden daghe

23. alghemeyne Kercke

25. noemt ghy die drye, den Vader

31. raedt Gods

32. een goede conscientie

37. met een eenigh soenoffer

39. een ander doodt

42. oock noch sterven moeten

48. even-wel persoonelick

69. waterbadt bevolen

75. so sekerlick spijst

77. Waer heeft ons Christus

85. bekeeringe
R 1913

en tot eene volkomene verlossing $(1595,1628)$

ten derde dage wederom

(Datheen, 1628)

algemeene, Christelike Kerk (1581, 1615)

noemt gij den Vader (1581, 1628)

raad en wille Gods $(1581,1615)$ een vrije en goede consciëntie $(1595,1628)$

met het eenige zoenoffer (1581, 1615)

met eenen anderen dood $(1581,1615)$ ook moeten sterven (1581, 1615)

niettemin ook in haar is en persoonlijk (Duits, Latyn, 1615)

waterbad ingezet $(1581,1615)$ zoo zekerlik tot het eeuwige leven spijst (Duits, Latyn, Datheen, 1615)

Waar heeft Christus (Duits, Latyn, 1581, 1615)

betering (Duits, Latyn, 1581, 1615) 
M 1611

86. uyt alle onse elendicheyt

90.

127. ende een ernstighe lust

konnen staende blijven
R 1913

uit onze ellendigheid (Duits, $1581,1615)$

en lust (Duits, Datheen, 1615)

kunnen bestaan (Duits, Latyn,

Datheen, 1615)

'n Derde groep wysigings het meer te doen met Rutgers se persoonlike voorkeur. In Antwoord 6 verkies hy om in plaas van 'gerechtigheid' te lees 'rechtvaardigheid' omdat die Statevertaling in Efesiërs 4: 24 so lees. Inderdaad is van die begin af na dié Skrifgedeelte verwys ter ondersteuning van die antwoord. Tog is 'geregtigheid' ná 1637 konsekwent gehandhaaf in Kategismusuitgawes en was Rutgers die eerste om die Statevertaling se lesing in te voer. In Antwoord 30 het $M 1611$ 'den eenighen Salighmaker Jesum' in plaas van 'den eenigen Heylant ende Salichmaker Jesum' wat in sommige vroeëre uitgawes van die Datheenteks voorkom in aansluiting by die Duitse teks. Die Latynse teks het van die begin af 'unicum Servatorem Iesum' gehad. Rutgers verkies hier dus om slegs 'Heiland' te lees omdat hy 'en Zaligmaker' as 'n oortollige byvoeging beskou. In Antwoord 36 kies Rutgers saam met die Duitse teks vir die kollektief 'zonde' in plaas van $M 1611$ se 'sonden' wat by die Latynse teks aansluit. Dit is opvallend dat hy hier bewustelik en met verantwoording die lesing van die Duitse teks kies, maar in Antwoord 2 'hoe groot mijne zonden en ellende zijn' saam met $M 1611$ behou, terwyl die Duitse teks ook daar die kollektief lees. In Antwoord 58 volg Rutgers weer eens die Statevertaling deur te kies vir 'in geens menschen hart opgeklommen is' soos dit in 1 Korintiërs 2: 9 staan, in plaas van $M 1611$ se '... gekomen is', wat getrou by die Duitse teks aansluit. In Antwoord 81 kies hy saam met Datheen en Van Toorenenbergen vir 'een oordeel' teenoor $M 1611$ se 'het oordeel' wat daarin die Duitse teks en die volledige Nederlandse tradisie minstens vanaf 1581 aan sy kant het. Rutgers se keuse vir 'heil' in plaas van 'salicheyt' in Antwoord 101 is goed begryplik en volkome in ooreenstemming met die Duitse en Latynse tekste. Daarteenoor is dit minder begryplik dat hy 'verdoemen' in Antwoord 112 wil vervang met 'veroordeelen', maar sy argument is dat 'verdoemen' oorspronklik 'veroordeel' beteken het.

Op 'n vierde groep wysigings hoef ons nie in te gaan nie. Dit is naamlik al die aanhalings uit die Heilige Skrif wat ná die verskyning van die Statebybel in 1637 en met elke aanpassing in die Nederlandse spelling gewysig is. 
Ná hierdie oorsig is dit duidelik dat in die dertiger en veertiger jare van hierdie eeu daar met weinig kennis uitsprake gemaak is oor A 1936 en sy bronteks. Die bewering dat daar in die teks van die formuliere van enigheid geen veranderinge aangebring is nie, kan nie stand hou nie, en net so min die bewering dat die Rutgersteks aanmerklik afwyk van die 'oorspronklike teks'. $R 1913$ staan immers nader aan Datheen 1566 as talle ander uitgawęs. Belangrikste van alles is egter dat ons in die Rutgersteks te doen het met 'n behoorlike wetenskaplike uitgawe. Met die aanvaarding in 1982 deur al drie Afrikaanse kerke van 'n vertaling wat eweneens na noukeurigheid streef, het daar gelukkig 'n einde gekom aan 'n lang tydperk van spanning tussen die kerke rondom die Afrikaanse teks van die Belydenisskrifte. Die hele hantering van die kategismusteks in Suid-Afrika mak die indruk van aan die een kant 'n sekere argeloosheid en aan die ander kant by tye 'n heftigheid sonder kennis.

Dit bly dan ook merkwaardig dat 'n ander aspek van die Rutgersteks stilswyend aanvaar is sonder enige amptelike sinodebesluit tot vandag toe. Dit is naamlik die stel Skrifverwysings wat deur $A 1936$ oorgeneem is en sindsdien in alle Afrikaanse uitgawes gehandhaaf word. Rutgers skryf in sy voorwoord 'dat de aan ieder antwoord toegevoegde Bijbelteksten ontleend zijn aan de Latijnsche uitgave, die in dit opzicht het nauwkeurigst is'. Dat hy sonder meer van 'de Latijnsch uitgave' praat, staan in opvallende spanning met die noukeurigheid wat hy elders in sy werk openbaar. Die Skrifverwysings wat hy opneem, is dié wat deur Vinke oorgeneem is uit die nagelate werke van Ursinus, soos gepubliseer deur Reuter in 1612 (Vinke 1846: LXII), en wat 'n aanmerklike verandering en vermeerdering vertoon teenoor die Skrifverwysings wat voorkom in die Latynse teks van 1563, terwyl Latyn 1563 op sy beurt weer heelwat verskil van die Duitse uitgawes van 1563 (Oberholzer 1986). Die onthullings van Doedes oor die 1563-Latynse teks was teen die tyd van Rutgers se arbeid reeds lank bekend (Doedes 1867).

Tot met die verskyning van $A 1936$ is in Suid-Afrika die Skrifverwysings gevolg wat in die Duitse uitgawes van 1563 en in die vroegste Datheen-uitgawes voorgekom het. Met die oorname van die 1612uitgawe se verwysings deur Rutgers (met 'n aantal korreksies), en deur A 1936 via Rutgers, het in Suid-Afrika 'n stel verwysings gevestig geraak sonder dat enige van die kerke daaroor 'n uitdruklike besluit geneem het. By implikasie is hierdie Skrifverwysings wel aanvaar toe die onderskeie kerke telkens 'n teks aanvaar het waarby die verwysings verskyn het, maar dit bly verbasend dat dit geen besondere aandag 
ontvang het nie. Die toepaslikheid al dan nie van die Skrifverwysings verdien afsonderlike behandeling. Kwantitatief is die verskille wel opvallend. By die 1612-teks verskyn daar sowat 1078 Skrifverwysings teenoor die sowat 836 in die Latynse teks van 1563 en die 685 in die eerste Duitse teks van 1563. Alles byeengenome, het die Kategismus se Suid-Afrikaanse gestalte ' $n$ interessante geskiedenis wat meer aandag verdien.

\section{Literatuurverwysings}

BAKHUIZEN VAN DEN BRINK, JN 1940 en 1976. De Nederlandsche Belijdenisgeschrifte. Amsterdam.

DIE HEIDELBERGSE KATEGISMUS, DEEL II 1930. Uitgegee op las van die Gereformeerde Kerke in Suid-Afrika vir gebruik in Huis, Katkikasie en Skool, vir meer gevorderde Kinders. Potchefstroom: Calvyn Jubileum Boekefonds.

DOEDES, JI 1867. De Heidelbergsche Catechismus in zijne eerste levensjaren 1563-1567, Utrecht.

DIE GEREFORMEERDE KERKE IN SUID-AFRIKA 1927, 1933, 1939. Handelinge van Sinodale Vergaderinge.

NEDERDUITS GEREFORMEERDE KERK IN SUID-AFRIKA 1936, 1940. Handelinge van die Sinodes.

NEDERDUITS GEREFORMEERDE KERK IN SUID-AFRIKA 1943. Skrywe van die Scriba Synodi aan ds TFJ Dreyer, 23 Julie 1943.

NEDERDUITSCH HERVORMDE KERK VAN AFRIKA. KOMMISSIE VAN DIE ALGEMENE KERKVERGADERING 1933. Notule van die Kommissie van die Algemene Kerkvergadering 6 September 1933, 205.

NEDERDUITSCH HERVORMDE KERK VAN AFRIKA. ALGEMENE KERKVERGADERINGE 1931, 1934, 1937, 1940, 1942. Notules van die Algemene Kerkvergadering.

OBERHOLZER, JP 1986. Die Heidelbergse Kategismus in vier teksuitgawes, met inleiding en teksvergelyking. Pretoria: Kital.

VINKE, HE 1846. Libri Symbolici Ecclesiae Reformatae Nederlandicae. Traiecti ad Rhenum. 